\title{
Micromesh-structured flexible polymer white organic light-emitting diodes using single emissive layer of blended polymer and quantum dots
}

\author{
Hsin-Ying Lee ${ }^{a}$, Po-Sung Su ${ }^{b}$, Ching-Ting Lee ${ }^{a, b, c, *}$ \\ a Department of Photonics, National Cheng Kung University, Tainan, 701, Taiwan, ROC \\ ${ }^{\mathrm{b}}$ Institute of Microelectronics, Department of Electrical Engineering, National Cheng Kung University, Tainan, 701, Taiwan, ROC ${ }^{\mathrm{C}}$ \\ Department of Electrical Engineering, Yuan Ze University, Taoyuan, 320, Taiwan, ROC
}

\section{ARTICLEINFO}

Keywords:

$\mathrm{CdSe} / \mathrm{ZnS}$ core-shell quantum dots

PVK polymer

$\mathrm{SiO}_{2}$ micromesh

White organic light-emitting diodes

\begin{abstract}
A B S T R A C T
In this study, poly(N-vinylcarbazole) was blended with $\mathrm{CdSe} / \mathrm{ZnS}$ core-shell quantum dots of various dimensions to be used as a single emissive layer of flexible polymer white organic light-emitting diodes (WOLEDs). A structure of WOLEDs was deposited on polyethylene terephthalate (PET) substrates. A luminance and maximum luminous efficiency of $4070.2 \mathrm{~cd} / \mathrm{m}^{2} \mathrm{and} 2.84 \mathrm{~cd} / \mathrm{A}$ were respectively obtained for the WOLEDs prepared using $n$-type gallium zinc oxide (GZO) and $n$-type indium gallium zinc oxide (IGZO) films as the electron transport layer and cathode, respectively. Because the current density can be increased by increasing the carrier transport surface area, the 2- $\mu \mathrm{m}$-periodic $\mathrm{SiO}_{2}$ micromesh was fabricated on PET substrates to enhance the surface area of $\mathrm{a} \mathrm{MoO}_{3}$ hole transport layer and a $\mathrm{GZO}$ electron transport layer. Furthermore, the GZO electron transport layer could provide a moisture barrier function. Compared with WOLEDs without the $\mathrm{SiO}_{2}$ micromesh, the prepared WOLEDs had an increased current density of 404.5 (compared with 222.8 ) $\mathrm{mA} / \mathrm{cm}^{2}$ when operating at $11 \mathrm{~V}$. Moreover, their associated luminance and maximum luminous efficiency increased to $7016.1 \mathrm{~cd} / \mathrm{m}^{2}$ and $3.04 \mathrm{~cd} / \mathrm{A}$, respectively.
\end{abstract}

\section{Introduction}

During the past half century, various inorganic materials and structures have successfully been used to fabricate inorganic light-emitting diodes (LEDs) and widely applied to various modules and systems. Recently, organic LEDs (OLEDs) have received considerable attention because of their inherent advantages, including wide viewing angle, self- emitting property, low cost, simple fabrication process, large-scale production, and flexibility [1,2]. Singlecolored OLEDs are widely used in various applications; however, white OLEDs (WOLEDs) are urgently required for applications in solid-state lighting fields, full-color flat-panel display system, and optical biosensors [3-5]. Resonant cavities, single emissive layers, and tandem-stacked layers are commonly developed to fabricate WOLEDs [6-8]. For simplifying fabrication, the single inherent advantages of quantum confinement for improving performance, various QDs have been widely used in LEDs [9-11]. In this work, the single emissive layer in flexible polymer WOLEDs was developed by blending poly ( $\mathrm{N}$ vinylcarbazole) (PVK) with various dimensional CdSe/ZnS core-shell QDs. Moreover, regarding the promising transparent $\mathrm{ZnO}$-based materials used in transparent thin-film transistors and solar cells $[12,13]$, $n$-type gallium zinc oxide (GZO) and n-type indium gallium zinc oxide (IGZO) films were used as an electron transport layer and a cathode electrode of flexible polymer WOLEDs, respectively. Furthermore, to fabricate a moisture barrier layer and to roughen the surface of a GZO electron transport layer, a $2-\mu \mathrm{m}$-periodic $\mathrm{SiO}_{2}$ micromesh was formed on flexible polyethylene terephthalate (PET) substrates by using a two-beam He-Cd laser interference photolithography system.

\footnotetext{
ctlee@ee.ncku.edu.tw (C.-T. Lee). https://doi.org/10.1016/j.orgel.2020.105722

2020

1566-1199/@ 2020 Elsevier B.V. All rights reserved.

emissive layer is a promising structure. However, to obtain white-light emission, various mixed organic materials are required in the single emissive layer. In addition to high color rendering, the emission of various colors of light can be achieved by quantum dots (QDs) with different dimensions. By considering the
}

* Corresponding author. Department of Electrical Engineering, Yuan Ze University, Taoyuan, 320, Taiwan, ROC. E-mail address:

Received 17 January 2020; Received in revised form 11 March 2020; Accepted 11 March 2020 Available online 23 March

\section{Experiment}

Fig. 1(a) and (b) illustrates the schematic configuration of flexible polymer WOLEDs without and with the $2-\mu \mathrm{m}$-periodic $\mathrm{SiO}_{2}$ micromesh, respectively. In 
a structure, 35-nm-thick n-type GZO layer, 65-nm-thick blended PVK with ODs (QDs:PVK) layer, and 10-nm-thick p-type

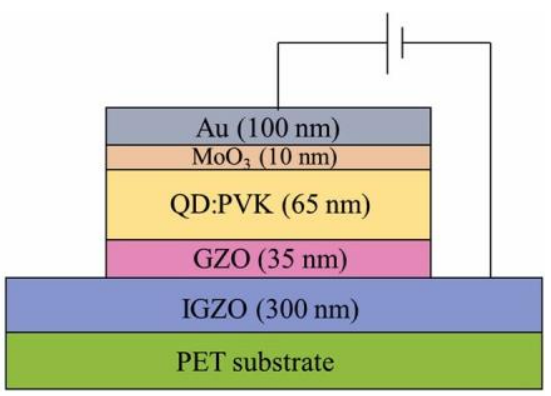

(a)

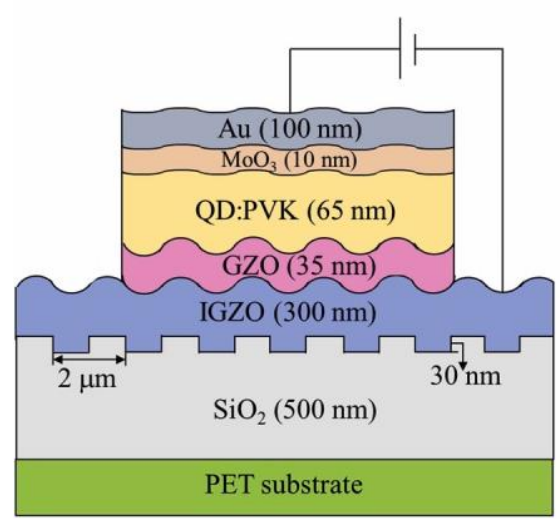

(b)

Fig. 1. Flexible polymer WOLEDs (a) without and (b) with the $2-\mu \mathrm{m}$-periodic $\mathrm{SiO}_{2}$ micromesh.

molybdenum oxide $\left(\mathrm{MoO}_{3}\right)$ layer were used as electron transport, single emissive, and hole transport layers, respectively. In addition, 300-nm- thick IGZO and 100-nm-thick gold ( $\mathrm{Au}$ ) layers were employed as a cathode and an anode, respectively. Furthermore, the $\mathrm{SiO}_{2}$ micromesh [Fig. 1 (b)] was used as the moisture barrier layer, and the surface roughness of the GZO electron transport layer was enhanced. A 500-nm- thick $\mathrm{SiO}_{2}$ film was first deposited on PET substrates by using an electron beam evaporator. Subsequently, a pattern of 2 - $\mu \mathrm{m}$-periodic $\mathrm{SiO}_{2}$ micromesh was obtained using a two-beam $\mathrm{He}-\mathrm{Cd}$ laser interference photolithography system in accordance with the process reported in Ref. [14]. The period of the $\mathrm{SiO}_{2}$ micromesh was obtained by changing the intersection angle of the two-beam He-Cd lasers. An etched 30-nm-thick $\mathrm{SiO}_{2}$ micromesh was obtained using a formed mask of a photoresist (AZ 6112) micromesh pattern by employing a chemical solution of buffered-oxide etch. Because the resulting $\mathrm{SiO}_{2}$ micromesh caused roughening of the $\mathrm{SiO}_{2}$ surface, the surface of subsequently deposited IGZO and GZO films was roughened to increase the carrier-injection surface area of the GZO electron transport layer. Fig. 2 (a) displays the top view of the 2 - $\mu$ m-periodic $\mathrm{SiO}_{2}$ micromesh obtained using a scanning electron microscope. Afterward, a 300-nm-thick IGZO and a 35-nm-thick GZO films were respectively deposited on the PET substrates and the $\mathrm{SiO}_{2}$ micromesh using a radio frequency (RF) magnetron sputter, sequentially. For fabricating the QDs:PVK single emissive layer, a dispersion solution of toluene, blended PVK, and various dimensional CdSe/ZnS core-shell QDs was first prepared. The dispersion solution was then stirred for 1 day and sonicated for $1 \mathrm{~h}$. The amounts of toluene, PVK, and total CdSe/ZnS core-shell QDs in the dispersion solution were $1 \mathrm{~mL}, 5 \mathrm{mg}$, and $25 \mathrm{mg}$, respectively (the weight ratio for QDs with a dimension of $5.2 \mathrm{~nm}, 4.2 \mathrm{~nm}, 1.6 \mathrm{~nm}$ was 1.5:1.3:2.2). The 65-nm-thick QDs:PVK single emissive layers were spread on GZO layers by employing the prepared dispersion solution and annealed in a glove box at $90 \mathrm{C}$ for $30 \mathrm{~min}$. Subsequently, a hole transport layer of a 10-nm- thick $\mathrm{MoO}_{3}$ film and an anode of a 100-nm-thick Au film were sequentially deposited on the QDs:PVK

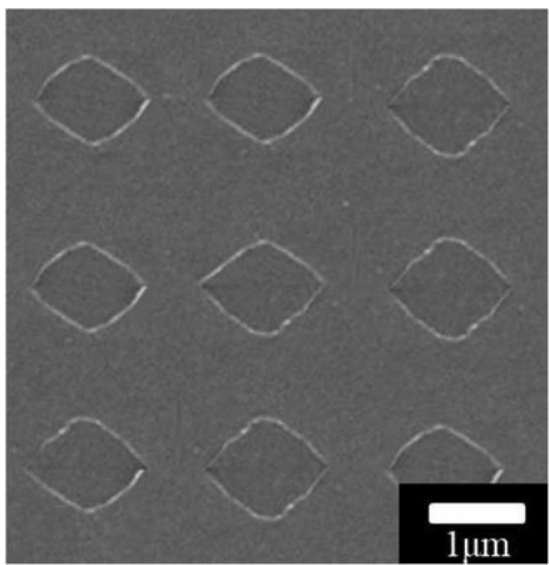

Fig. 2. Scanning electron microscope image of top view of $2-\mu \mathrm{m}$-periodic $\mathrm{SiO}_{2}$ micromesh

single emissive layer by using a thermal evaporator. To study the electrical properties of 35-nm-thick GZO and 300-nm-thick IGZO films, they were deposited on PET substrates through RF magnetron sputter deposition.

3. Results and discussion The electron concentration of $7.8610^{20} \mathrm{~cm}^{3}$ and 1.07 $10^{21} \mathrm{~cm}^{3}$ and the electron mobility of $4.20 \mathrm{~cm}^{2} / \mathrm{V}$-s and $9.96 \mathrm{~cm}^{2} / \mathrm{V}$-s were respectively obtained for 35 -nm-thick GZO and 300-nm-thick IGZO films by using Hall measurement, and their associated resistivities were $1.6710^{3}$ and $5.0810^{4} \Omega^{-\mathrm{cm}}$, respectively.

Fig. 3 presents the photoluminescence spectra of PVK and CdSe/ZnS coreshell QDs that were obtained using the $\mathrm{He}-\mathrm{Cd}$ laser as an excited source and normalized with respect to a green emissive intensity by employing $5 \mathrm{mg}$ of each used material. The emission peaks of QDs with a dimension of $1.6 \mathrm{~nm}, 4.2$ $\mathrm{nm}, 5.2 \mathrm{~nm}$ appeared at 451 (blue color), 523 (green color), and $611 \mathrm{~nm}$ (red color), respectively. The white emission could be obtained by varying the content of various dimensional CdSe/ ZnS QDs. By using the weight ratio of 1.5:1.3:2.2 for the RGB emissive quantum dots, the Commission Internationale del' Eclairage (CIE) of $(0.33,0.33)$ was obtained for both the WOLEDs without and with the 2- $\mu$ m-periodic $\mathrm{SiO}_{2}$ micromesh (Fig. 4). Its associated color rendering index (CRI) was 73.2. The $\mathrm{SiO}_{2}$ micromesh and roughened surface of the GZO electron transport layers did not influence white emission.

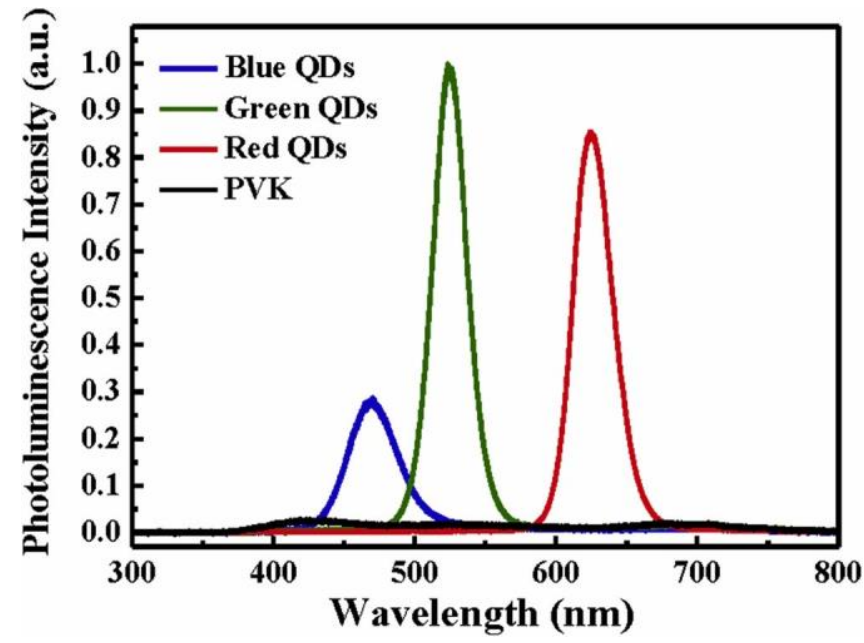

Fig. 3. Normalized photoluminescence spectra of PVK and CdSe/ZnS core-shell QDs with dimension of $5.2,4.2$, and $1.6 \mathrm{~nm}$. 


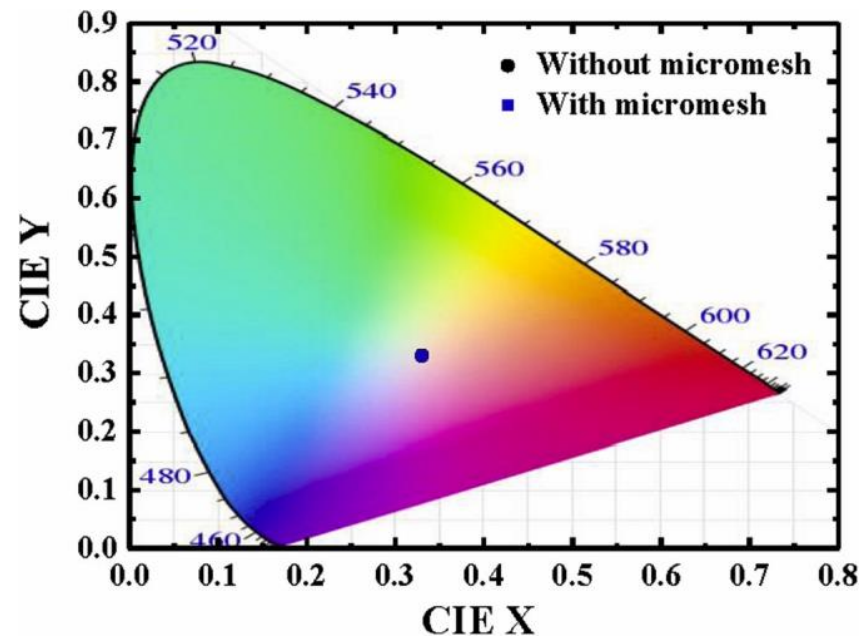

Fig. 4. $\mathrm{CIE}$ coordinate of WOLEDs without and with the 2- $\mu \mathrm{m}$-periodic $\mathrm{SiO}_{2}$ micromesh.

Fig. 5 presents current density as a function of voltage applied to WOLEDs without and with the 2.0- $\mu \mathrm{m}$-periodic $\mathrm{SiO}_{2}$ micromesh. Current density was increased in WOLEDs with $\mathrm{SiO}_{2}$ micromesh. The current density of WOLEDs without and with the 2- $\mu \mathrm{m}$-periodic $\mathrm{SiO}_{2}$ micromesh at an applied voltage of $11 \mathrm{~V}$ were 222.8 and $404.5 \mathrm{~mA} / \mathrm{cm}^{2}$, respectively. The surface area of $\mathrm{MoO}_{3}$ hole transport layer and $\mathrm{GZO}$ electron transport layer roughened by the $\mathrm{SiO}_{2}$ micromesh was larger than that of the flat $\mathrm{MoO}_{3}$ hole transport layer and flat GZO electron transport layer. Consequently, the increase in current density was attributed to the larger carrier injection surface area. The inset of Fig. 5 illustrates the dependence of luminance on the applied voltage. When the applied voltage was $11 \mathrm{~V}$, the luminance of 4070.2 and $7016.1 \mathrm{~cd} / \mathrm{m}^{2}$ was obtained for WOLEDs without and with the $2-\mu \mathrm{m}$-periodic $\mathrm{SiO}_{2}$ micromesh, respectively. The luminance of WOLEDs with the $\mathrm{SiO}_{2}$ micromesh was greater than that of WOLEDs without the $\mathrm{SiO}_{2}$ micromesh for the same applied voltage. Moreover, regarding to the low carrier transportation velocity in the QDs:PVK single emissive layer owing to the low carrier mobility, the carrier recombination opportunity would be increased by shortening the propagation distance caused by the surface roughness of both the surfaces. It was deduced that the increased carrier recombination opportunity would increase its emissive

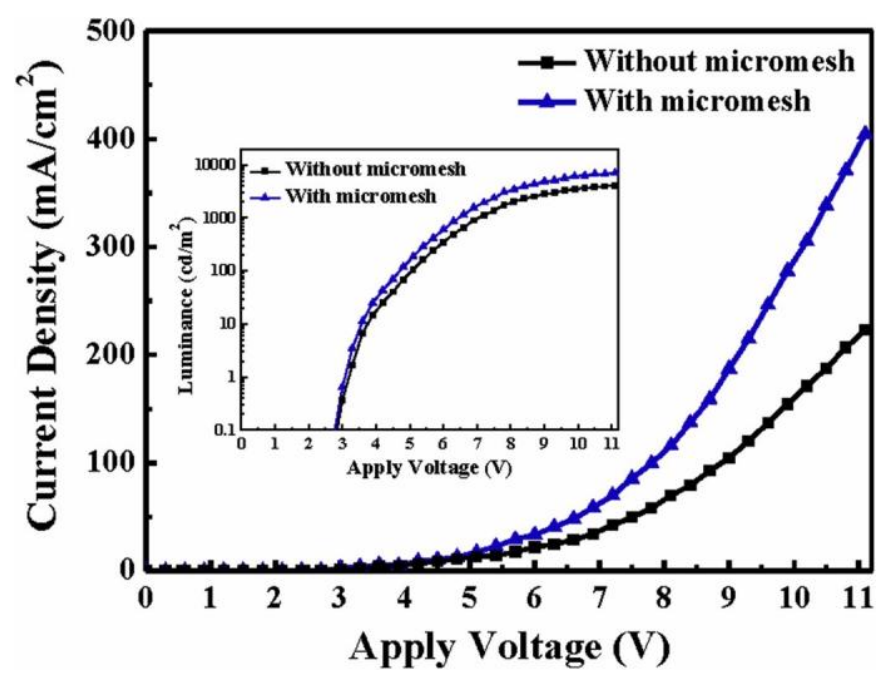

luminance. Consequently, the phenomenon of improve luminance was attributed to a larger injection current density and a larger carrier Fig. 5. Current density as a function of voltage applied to WOLEDs without and with the 2 - $\mu \mathrm{m}$-periodic $\mathrm{SiO}_{2}$ micromesh. The inset shows associated dependence of luminance on applied voltage. recombination opportunity obtained in the WOLEDs with the $\mathrm{SiO}_{2}$ micromesh for the same applied voltage. Luminance gradually saturated at a higher applied voltage.

Fig. 6 presents luminous efficiency as a function of voltage applied to WOLEDs without and with the $\mathrm{SiO}_{2}$ micromesh. At the same applied voltage, the WOLEDs with the $\mathrm{SiO}_{2}$ micromesh had higher luminous efficiency than the WOLEDs without the $\mathrm{SiO}_{2}$ micromesh. This phenomenon was attributed to the larger luminance of WOLEDs with the $\mathrm{SiO}_{2}$ micromesh. In both WOLEDs, the luminous efficiency increased with an increase in the applied voltage until the voltage corresponded to the peak luminous efficiency, and then its luminous efficiency decreased with a further increase of apply voltage. Because the injection current density increased with an increase in the applied voltage, a larger current density led to a higher hole-electron recombination rate via QDs, which enhanced luminance and the associated luminance efficiency. However, because the total number of QDs within the QDs:PVK single emissive layer was kept constant, it was deduced that the injection current density was restricted for obtaining effective hole-electron recombination via QDs. Consequently, the luminance of WOLEDs was gradually saturated by applying a higher injection current density caused by a higher apply voltage (as shown in the inset of Fig. 5). The luminous efficiency gradually decreased with an increase in the applied voltage beyond the voltage corresponding to the maximum luminous efficiency. For WOLEDs without and with the $2-\mu \mathrm{m}$-periodic $\mathrm{SiO}_{2}$ micromesh, the maximum luminous efficiency of 2.84 and $3.04 \mathrm{~cd} / \mathrm{A}$ were respectively obtained at the applied voltage of 8.1 and $7.8 \mathrm{~V}$. The applied voltage corresponding to the maximum luminous efficiency of WOLEDs with the 2- $\mu \mathrm{m}$ periodic $\mathrm{SiO}_{2}$ micromesh was lower than that of WOLEDs without the $\mathrm{SiO}_{2}$ micromesh. This phenomenon was attributed to the fact that the injection current density required for saturating effective hole-electron recombination via QDs was obtained by applying a lower voltage to the WOLEDs with the 2$\mu \mathrm{m}$-periodic $\mathrm{SiO}_{2}$ micromesh.

\section{Conclusions}

In this work, a single emissive layer constructed by blending PVK with various dimensional $\mathrm{CdSe} / \mathrm{ZnS}$ core-shell QDs was employed to fabricate flexible polymer WOLEDs on PET substrates. RGB light could be emitted through CdSe/ZnS QDs with the dimensions of $5.2,4.2$, and $1.6 \mathrm{~nm}$, respectively. By using the weight ratio of 1.5:1.3:2.2 for RGB emissive QDs, the $\mathrm{CIE}$ coordinate and $\mathrm{CRI}$ of $(0.33,0.33)$ and 73.2 were respectively obtained for WOLEDs. The luminance and the maximum

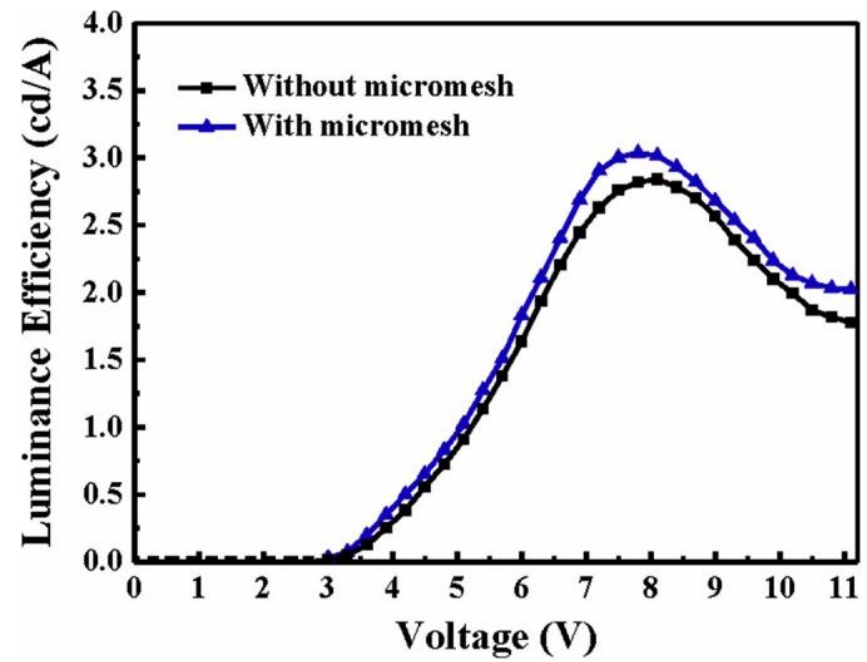


luminous efficiency of $4070.2 \mathrm{~cd} / \mathrm{m}^{2}$ and $2.84 \mathrm{~cd} / \mathrm{A}$ were obtained using $35-\mathrm{nm}$ thick GZO and 300-nm-thick IGZO films as the electron transport layer and cathode, respectively. To increase current density by roughening the surface of the $\mathrm{MoO}_{3}$ hole transport layer and the $\mathrm{GZO}$ electron transport layer, twobeam $\mathrm{He}-\mathrm{Cd}$ laser interference photolithography system was performed to pattern the $2-\mu \mathrm{m}$-periodic $\mathrm{SiO}_{2}$ micromesh. Compared with the WOLEDs without the $\mathrm{SiO}_{2}$ micromesh, the WOLEDs with the $2-\mu \mathrm{m}$-periodic $\mathrm{SiO}_{2}$ micromesh obtained an increased current density of 404.5 (compared with 222.8) $\mathrm{mA} / \mathrm{cm}^{2}$ when operating at $11 \mathrm{~V}$. Furthermore, the associated luminance and maximum luminous efficiency of the WOLEDs with the $\mathrm{SiO}_{2}$ micromesh operated at the same applied voltage increased to $7016.1 \mathrm{~cd} / \mathrm{m}^{2}$ and $3.04 \mathrm{~cd} / \mathrm{A}$, respectively. Declaration of competing interest

The authors declare that they have no known competing financial interests or personal relationships that could have appeared to influence the work reported in this paper.

\section{Acknowledgement}

This work was supported by the Ministry of Science and Technology of the Republic of China under contract No. MOST 108-2221-E-006-215- MY3, MOST 108-2221-E-155-029-MY3, and MOST-108-2221-006-196- MY3.

\section{References}

1. Zhang, Y. F.; Xu, Z.; Zhang, F. J.; Wang, Y.; Zhao, S. L., White organic light emitting device with dyestuff DCJTB mended in polymer. Spectroscopy and Spectral Analysis 2008, 28 (4), 760-762.

2. Watanabe, K.; Sakamoto, T.; Taguchi, M.; Fujiki, M.; Nakano, T., A chiral pi-stacked vinyl polymer emitting white circularly polarized light. Chem. Commun. 2011, 47 (39), 10996-10998.

3. Wang, R.; Peng, J.; Qiu, F.; Yang, Y. L., Enhanced white-light emission from multiple fluorophores encapsulated in a single layer of diblock copolymer micelles. Chem. Commun. 2011, 47, 2787-2789

4. Prakash, A.; Katiyar, M., White polymer light emitting diode using blend of fluorescent polymers. 16th International Workshop on Physics of Semiconductor Devices 2012, 8549.

5. Park, J. J.; Park, T. J.; Jeon, W. S.; Kim, S. Y.; Lee, Y. K.; Jang, J.; Kwon, J. $\mathrm{H}$., White Polymeric Light-Emitting Diodes Based on Doping of an Orange Ir Complex in a Fluorene Blue Polymer Host. Mol. Cryst. Liq. Cryst. 2009, 498, 290-297.

6. Park, J. J.; Park, T. J.; Jeon, W. S.; Kim, S. Y.; Lee, Y. K.; Jang, J.; Kwon, J. $\mathrm{H}$. , White polymeric light-emitting diodes based on doping of an orange $\mathrm{Ir}$ complex in a fluorene blue polymer. Idw '07: Proceedings of the 14th International Display Workshops, Vols 1-3 2007, 1033-1036.

7. Nicolai, H. T.; Hof, A. J.; Blom, P. W. M., Charge transport in white lightemitting polymers. Organic Optoelectronics and Photonics li 2006, 6192. 8. Nicolai, H. T.; Hof, A.; Blom, P. W. M., Device Physics of White Polymer Light-Emitting Diodes. Adv. Funct. Mater. 2012, 22 (10), 2040-2047. 9. Li, B. N.; Liu, L.; Fu, G. R.; Zhang, Z.; Li, H. Y.; Lu, X.; Wong, W. K.; Jones, R. A., Color-tunable to direct white-light and application for white polymer light emitting diode (WPLED) of organo-Eu3+- and organo-Tb3+doping polymer. J. Lumin. 2017, 192, 1089-1095.

10. Shen, F. Z.; He, F.; Lu, D.; Xie, Z. Q.; Xie, W. J.; Ma, Y. G.; Hu, B., Bright and colour stable white polymer light-emitting diodes. Semiconductor Science and Technology 2006, 21 (2), L16-L19.

11. Kim, C.; Gwon, Y. J.; Kim, J.; Lee, T. S., Synthesis of fluorescent conjugated polymer nanoparticles and their immobilization on a substrate for white light emission. Polym Chem-Uk 2018, 9 (48), 5671-5679.

12. Amin, G.; Zaman, S.; Zainelabdin, A.; Nur, O.; Willander, M., ZnO nanorods-polymer hybrid white light emitting diode grown on a disposable paper substrate. Physica Status Solidi-Rapid Research Letters 2011, 5 (2), 7173.

13. Taudt, C.; Baselt, T.; Oreski, G.; Hirschl, C.; Koch, E.; Hartmann, P., Cross-linking characterization of polymers based on their optical dispersion
H.-Y. Lee et al.

Electronics 82 (2020) 105722

Fig. 6. Luminous efficiency as a function of voltage applied to WOLEDs without and with the 2- $\mu$ m-periodic $\mathrm{SiO}_{2}$ micromesh.

utilizing a white-light interferometer. Optical Measurement Systems for Industrial Inspection Ix 2015, 9525.

14. Song, H. J.; Shin, G. J.; Choi, K. H.; Lee, S.; Moon, D. K., White polymer light emitting diode materials introducing dendritic quinoxaline derivative: Synthesis, optical and electroluminescent properties. Synthetic Metals 2014, 190, 1-7.

15. Lee, H. K.; Kim, T. H.; Park, J. H.; Kim, J. K.; Park, O. O., White-lightemitting diodes using miscible polymer blend doped with phosphorescent dye. Organic Electronics 2011, 12 (6), 891-896.

16. Kim, J. H.; Song, W. S.; Yang, H., Color-converting bilayered composite plate of quantum-dot-polymer for high-color rendering white light-emitting diode. Opt. Lett. 2013, 38 (15), 2885-2888.

17. Kassamakov, I.; Ojala, K.; Salmia, A.; Haeggstrom, E.; Aaltonen, J.; Huber, A.; Saarikko, H.; Osterberg, M.; Oinonen, M., Characterization of dents and grooves on polymer films using scanning white light interferometry. Optical Micro- and Nanometrology in Microsystems Technology 2006, 6188.

18. Inoue, A.; Hosokawa, T.; Haishi, M.; Ohtani, N., 4-(dicyanomethylene)2-methyl-6-(p-dimethylaminostyryl)-4H-pyran (DCM)-doping density dependence of luminescence spectra and white emission in polymer lightemitting diodes. Physica Status Solidi C - Current Topics in Solid State Physics, Vol 6, No 1 2009, 6 (1), 334-337.

19. Hu, B.; Yao, C.; Huang, X. R., Designing of the White-Light Emission from a Single-Polymer System: Quantum Theoretical Study. Polymer Science Series A 2011, 53 (11), 1097-1105.

20. Fan, L. M.; Fan, W. L.; Li, B.; Zhao, X.; Zhang, X. T., W-shaped 1,3di(2,4-dicarboxyphenyl)benzene based lanthanide coordination polymers with tunable white light emission. New J. Chem. 2016, 40 (12), 10440-10446. 21. da Silva, M. A. T.; Thomazini, E. F.; Albertini, M.; Renzi, W.; Franchello, F.; Dias, I. F. L.; Duarte, J. L.; Pocas, L. C.; Lourenco, S. A., Characterization of digital textile printing and polymer blend (PFO-DMP:P3HT) for application in manufacture of organic diodes emitting white light - WOLEDS. Optical Materials 2016, 62, 119-131.

22. Chen, M. X.; Sun, R. Y.; Ye, Y. C.; Tang, H. J.; Dong, X. Y.; Yan, J. L.; Wang, K. M.; Zhou, Q.; Wang, Z. L., Application of a novel red-emitting cationic iridium(III) coordination polymer in warm white light-emitting diodes. Optical Materials 2018, 76, 141-146.

23. Wang, R.; Peng, J.; Qiu, F.; Yang, Y. L.; Xie, Z. Y., Simultaneous blue, green, and red emission from diblock copolymer micellar films: a new approach to white-light emission. Chem. Commun. 2009, (44), 6723-6725. 24. Hrma, M.; Sichova, K.; Svoboda, J.; Vohlidal, J., Assembling of bis(tpy)fluorenes with Zn2+ and Fe2+ ions into metallo-supramolecular polymers with highly efficient white-light emission. Polymer 2017, 122, 2233.

25. Chitara, B.; Bhat, S. V.; Vivekchand, S. R. C.; Gomathi, A.; Rao, C. N. R., White-light sources based on composites of GaN nanocrystals with conducting polymers and nanophosphors. Solid State Communications 2008, 147 (9-10), 409-413.

26. Cheng, G.; Fei, T.; Zhao, Y.; Ma, Y. G.; Liu, S. Y., White phosphorescent polymer light-emitting devices based on a wide band-gap polymer derived from 3,6-carbazole and tetraphenylsilane. Organic Electronics 2010, 11 (3), 498-502.

27. Chen, S. A.; Chang, E. C.; Chuang, K. R.; Chao, C. I.; Wei, P. K.; Fann, W. S., Conjugated polymer blends as emitting layer for white light led. Abstr. Pap. Am. Chem. Soc. 1998, 215, U392-U392.

28. Zhen, H. Y.; Xu, W.; King, W.; Chen, Q. L.; Xu, Y. H.; Jiang, J. X.; Peng, J. B.; Cao, Y., White-light emission from a single polymer with singlet and triplet chromophores on the backbone. Macromol. Rapid Commun. 2006, 27 (24), 2095-2100.

29. Zhang, T. H.; Gong, Z. C.; Que, L., A white-light source operated polymer-based micromachined Fabry-Perot chemo/biosensor. 2009 4th leee International Conference on Nano/Micro Engineered and Molecular Systems, Vols 1 and 2 2009, 181-184.

30. Willander, M.; Nur, O.; Zaman, S.; Zainelabdin, A.; Bano, N.; Hussain, I., Zinc oxide nanorods/polymer hybrid heterojunctions for white light emitting diodes. J. Phys. D: Appl. Phys. 2011, 44 (22). 
31. Wang, Z. W.; Gao, D. Z.; Ma, X. J.; Meng, J., White-Light Interferometry for Measuring Fuel Pressure in Icf Polymer-Microsphere Targets. Fusion Sci. Technol. 2014, 66 (3), 432-437.

32. Wang, B. Z.; Zhang, X. P.; Liu, H. M., White-light-emitting diode based on a single-layer polymer. Aip Advances 2013, 3 (5).

33. Tian, L. L.; Zhang, W.; Yang, B.; Lu, P.; Zhang, M.; Lu, D.; Ma, Y. G.; Shen, J. C., Zinc(II)-induced color-tunable fluorescence emission in the piconjugated polymers composed of the bipyridine unit: A way to get whitelight emission. J. Phys. Chem. B 2005, 109 (15), 6944-6947.

34. Tang, K. C.; Tseng, S. R.; Li, W. S.; Meng, H. F.; Horng, S. F.; Hsu, C. S., Broad band and white phosphorescent polymer light-emitting diodes in multilayer structure. Synthetic Metals 2008, 158 (7), 287-291.

35. Sun, C.; Zhang, Y.; Sun, K.; Reckmeier, C.; Zhang, T. Q.; Zhang, X. Y.; Zhao, J.; Wu, C. F.; Yu, W. W.; Rogach, A. L., Combination of carbon dot and polymer dot phosphors for white light-emitting diodes. Nanoscale 2015, 7 (28), 12045-12050.

36. Roberts, R. J.; Le, D.; Leznoff, D. B., Color-Tunable and White-Light Luminescence in Lanthanide Dicyanoaurate Coordination Polymers. Inorg. Chem. 2017, 56 (14), 7948-7959.

37. Qin, L. J.; Zhu, Y. C.; Yang, H.; Ding, L.; Sun, F.; Shi, M.; Yang, S. P., White-light phosphorescence from binary coordination polymer nanoparticles. Mater. Chem. Phys. 2013, 139 (2-3), 345-349.

38. Ovens, J. S.; Christensen, P. R.; Leznoff, D. B., Designing Tunable WhiteLight Emission from an Aurophilic Cu-l/Au-I Coordination Polymer with Thioether Ligands. Chemistry-a European Journal 2016, 22 (24), 8234-8239. 39. Niu, Y. H.; Liu, M. S.; Ka, J. W.; Bardeker, J.; Zin, M. T.; Schofield, R.; Chi, Y.; Jen, A. K. Y., Crosslinkable hole-transport layer on conducting polymer for high-efficiency white polymer light-emitting diodes. Adv. Mater. 2007, 19 (2), 300-+.

40. Niu, W. Y.; Sun, J. W.; Yan, P. F.; Li, Y. X.; An, G. H.; Li, G. M., 2D I-Ditoluoyl-tartaric acid Lanthanide Coordination Polymers: Toward Singlecomponent White-Light and NIR Luminescent Materials. Chemistry-an Asian Journal 2016, 11 (4), 555-560.

41. Nam, G. H.; Park, I. K., CdSe Quantum dot-conducting polymer hybrid structure for Phosphor-free white light-emitting diodes. Journal of the Korean Physical Society 2015, 66 (5), 785-789.

42. Meng, L. C.; Lou, Z. D.; Yang, S. Y.; Hou, Y. B.; Teng, F.; Liu, X. J.; Li, Y. $B .$, White organic light-emitting diodes based on a combined electromer and monomer emission in doubly-doped polymers. Chinese Physics B 2012, 21

(8). 